\title{
Characterization of hydrochlorothiazide in solid formulations
}

\author{
Simone T. B. de Salvi, ${ }^{\text {a) }}$ Diego Luiz Tita, Carlos de O. Paiva-Santos, and Selma G. Antonio \\ Univ. Estadual Paulista - UNESP. Araraquara - SP, Brazil
}

(Received 30 September 2014; accepted 10 March 2015)

\begin{abstract}
Hydrochlorothiazide (HCTZ) is a diuretic used for the treatment of blood pressure (hypertension). HCTZ has two anhydrous polymorphs denoted as Forms I and II. Aiming at solid-state characterization, X-ray powder diffraction (XRPD) is known to be a powerful technique which has been successfully applied in investigating polymorphism in medicines. In this work, three tablets of HCTZ (a reference and two generic) were analyzed. The data were collected using Rigaku RINT2000 diffractometer copper rotate anode. The Rietveld method (RM) was applied for the characterization of HCTZ polymorphic form. For the crystalline excipients where the crystal structure is known, their phases were identified by the RM either. The results showed that all the tablets exhibit Form I of HCTZ, while the excipient lactose monohydrate is found to exhibit the crystalline form. One of the generics is also found to exhibit the excipient sodium lauryl sulfate (SLS) in the crystalline form. Therefore, the RM and XRPD are an efficient methodology for characterization of the crystalline Form I of the active principle of HCTZ and crystalline excipients lactose monohydrate and SLS in solid formulations. It is also interesting to observe excipients not described in the package insert of the medicament. (c) 2015 International Centre for Diffraction Data. [doi:10.1017/S0885715615000226]
\end{abstract}

Key words: Hydrochlorothiazide, polymorphism, X-ray powder diffraction, Rietveld Method

\section{INTRODUCTION}

Hydrochlorothiazide (HCTZ), shown in Figure 1, is a diuretic that is widely used in antihypertensive therapies.

HCTZ exhibits two crystal structures known as Forms I and II. Form I (Space Group: $P 2_{1}$ ) is known to have been reported by L. Dupont and O. Dideberg (CSD [Structural Database. Established in 1965, the CSD is the world's repository for small-molecule organic crystal structures]: HCSBTZ) (Dupont and Dideberg, 1972) while Form II (Space Group: $P 2{ }_{1} / c$ ) was reported in the work of A. Florence et al. (CSD: HCSBTZ01) (Florence et al., 2005).

According to Johnston et al., 2007, Form II is said to be the metastable one, whereas Form I, which corresponds to the commercial form, is known to be the one with the highest stability. (Johnston et al., 2007).

The polymorphic characterization can be developed by several techniques, among them including spectroscopic (IR, Raman, NMR) (Brittain, 1997; Guo et al.,) (Brittain, 1997; Linck et al.,), thermal analysis (TG, DTA, DSC), and microscopic (SEM, TEM, FEG). Another widely applied technique is X-ray powder diffraction (XRPD). Largely used in solidstate characterization, the XRPD when combined with the Rietveld Method (RM) (Rietveld, 1969), is remarkably an interesting tool used for the characterization as well as the quantification of crystalline phases.

Manufacturing processes such as milling, recrystallization, drying, etc. may change the powder properties and are likely to exert an influence over the stability and the dissolution of a solid pharmaceutical formulation.

\footnotetext{
a) Author to whom correspondence should be addressed. Electronic mail: simonebonemer@yahoo.com.br
}

In the present study, the polymorphic form of HCTZ was investigated in commercial formulations of HCTZ using the RM and XRPD data. The excipients of these tablets were also characterized.

\section{EXPERIMENTAL}

Commercial tablets were purchased from some drugstores located in the city of Araraquara (São Paulo State, Brazil). The medicaments acquired included a reference one (sample $\mathrm{R}$ ) and two generics (samples G-01 and G-02, respectively), all the formulations were of $25 \mathrm{mg}$. The coating of the tablets was removed and the tablets were then ground and sieved, the fine powder was pressed in a flat-plate sample holder. The data were collected using a Rigaku RINT2000 cooper $(\mathrm{CuK \alpha})$ rotating anode diffractometer operating at $42 \mathrm{kV}$ and $120 \mathrm{~mA}$. A receiving slit of $0.3 \mathrm{~mm}$, a $2.5^{\circ}$ divergence Soller slit and curved graphite monochromator in the diffracted beam were used. The data were collected in the $2 \theta$ scan range $2^{\circ}-40^{\circ}$, at room temperature. The refinements were performed using TOPAS Academic v.5 software (Coelho, 2007). A fundamental parameters model implemented in the program was used to adjust the peak broadening (Cheary et al., 2004). The crystallite size was refined considering an anisotropic form, having independent Lorentzian and Gaussian components to the family plans $(h 00),(0 k 0),(001),(h k 0),(h 01)$,

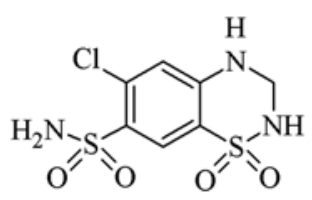

Figure 1. Molecular structure of hydrochlorothiazide. 
TABLE I. Package insert information for the three medicaments analyzed; samples R (the reference medicament), G-01, and G-02 (two generics).

\begin{tabular}{lllll}
\hline \hline & & \multicolumn{2}{l}{ Samples } & \\
\cline { 3 - 5 } & & reference & Generics & \\
\cline { 3 - 5 } & & $\mathrm{R}$ & $\mathrm{G}-01$ & $\mathrm{G}-02$ \\
\hline Presentation & & $25 \mathrm{mg}$ & $25 \mathrm{mg}$ & $25 \mathrm{mg}$ \\
Excipients & Cellulose microcrystalline & & $\mathrm{X}$ & \\
& Crospovidone & & & $\mathrm{X}$ \\
& Lactose monohydrate & $\mathrm{X}$ & $\mathrm{X}$ & $\mathrm{X}$ \\
& Magnesium stearate & $\mathrm{X}$ & $\mathrm{X}$ & $\mathrm{X}$ \\
& $\begin{array}{l}\text { Pregelatinized starch } \\
\text { PVP 30 }\end{array}$ & & $\mathrm{X}$ & $\mathrm{X}$ \\
& Starch & $\mathrm{X}$ & & \\
\hline \hline
\end{tabular}

${ }^{\mathrm{a}}$ This crystal phase was identified in the refinement.

and $(h k l)$, an approximation of the Double-Voigt model which is implemented in the software TOPAS Academic v.5 (Balzar, 1993). A Chebyschev polynomial was used to adjust the background (Chebyshev, 1854). The preferred orientation feature was corrected using the Spherical Harmonics model (Järvinen, 1993). The unit-cell parameters of HCTZ Form I and excipients were refined, but the atomic coordinates of the crystal phases were not.

\section{RESULTS AND DISCUSSIONS}

The information on the package insert of the medicaments is in Table I, where the excipients presented in each formulation can clearly be found. The crystal structure of HCTZ Form I was employed in the refinement of the three samples, which does not present the peaks of Form II of this drug.

Lactose monohydrate is an excipient which is largely used in tablets production, and it is usually found in the crystalline form. The X-ray powder pattern of lactose monohydrate (space group: $P 2_{1}$ ) (Fries et al., 1971) was found in the tablets, and its crystal structure model was employed in the refinement.

Table II shows the cell parameters of the crystal structures that were employed in the refinements. It is worth noting that the sodium lauril sulfate (SLS) does not belong to the package insert of the medicament, but its characteristic peaks are present in the diffractogram of the G-02 sample, which was characterized during the refinement.

\section{A. Refinements}

\section{Sample $R$}

The reference tablet, sample $\mathrm{R}$, presented Form I of HCTZ and the peaks of a crystalline lactose monohydrate excipient. The Rietveld plot of this sample is shown in Figure 2, where the adequate agreement of the profile fitting can be observed. The Rietveld plot shows the observed powder pattern (o), the calculated pattern (continuous line), the difference between the calculated and the observed patterns, and the Bragg peak positions (I). This tablet contains other excipients, as can be observed in Table I, though they do not exhibit peaks. This sample contains amorphous starch, cellulose microcrystalline, crospovidone, and polyvinylpyrrolidone (PVP). In the package insert, it can be found that the excipient magnesium stearate is cited. This excipient is normally crystalline and tend to exhibit its most intense peak at $2 \theta \sim 5.5^{\circ}$. Though, no peak of this excipient was observed in this position in the diffractogram. The quantitative phase analysis from the RM only quantifies crystalline phases and, in this case, there are some amorphous phases of the above-mentioned excipients. Thus, the results do not represent all the components of the tablet but only the crystalline phases. Sample R exhibited 14.4(1)

TABLE II. Cell parameters of the crystal structures employed in the refinements.

\begin{tabular}{|c|c|c|c|c|c|c|}
\hline Crystal structure & Space group & $a(\AA)$ & $b(\AA)$ & $c(\AA)$ & $\beta\left(^{\circ}\right)$ & Reference \\
\hline Form I & $P 2_{1}$ & $7.419(6)$ & $8.521(3)$ & $10.003(2)$ & 111.72 & CSD: HCSBTZ (Dupont and Dideberg, 1972) \\
\hline $\mathrm{LM}^{\mathrm{a}}$ & $P 2_{1}$ & $7.982(2)$ & $21.562(3)$ & $4.824(1)$ & $109.57(3)$ & CSD: LACTOS 10 \\
\hline SLS $^{\mathrm{b}}$ & $P 2_{1} / c$ & 38.915 & 4.709 & 8.198 & 93.29 & CSD: VECYOR01 \\
\hline
\end{tabular}

${ }^{\mathrm{a}} \mathrm{LM}$, lactose monohydrate.

${ }^{\mathrm{b}} \mathrm{SLS}$, sodium lauryl sulfate.

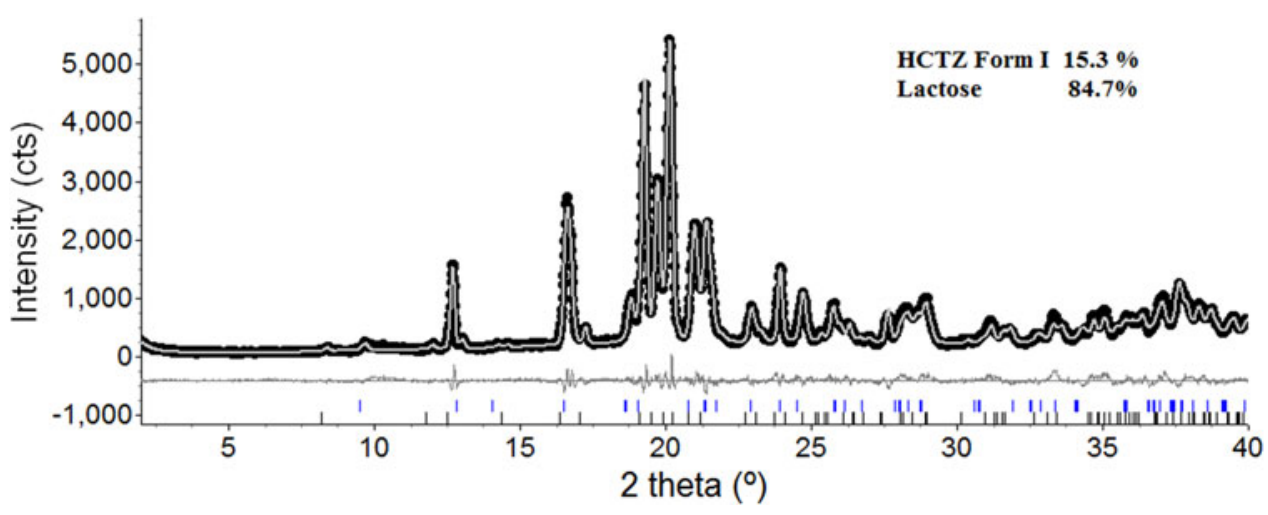

Figure 2. (Color online) Rietveld plot of the reference sample, showing Form I of HCTZ and the crystalline excipient lactose monohydrate. 


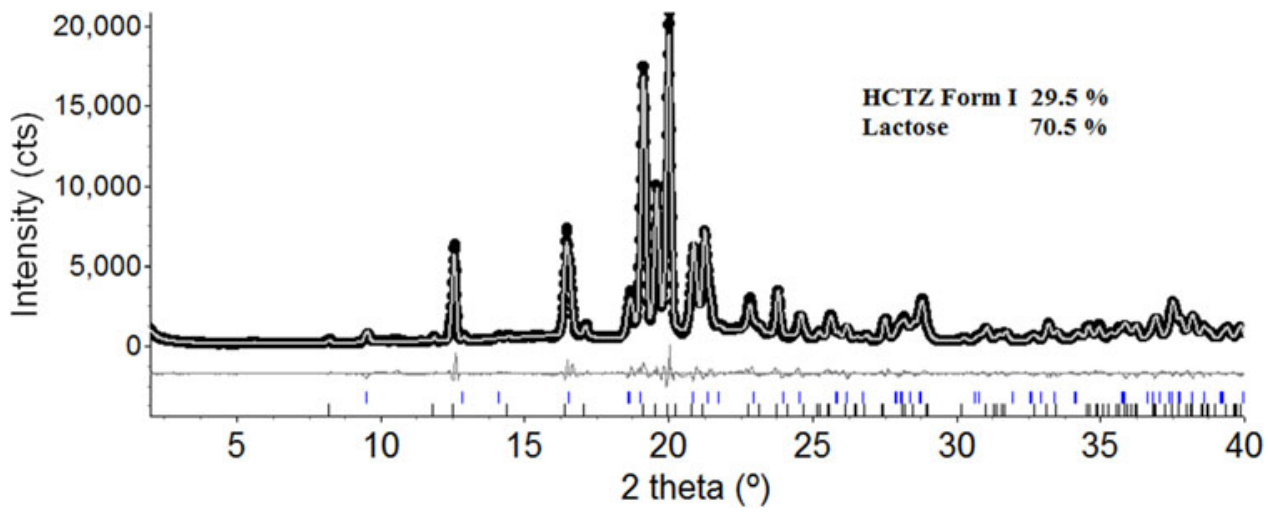

Figure 3. (Color online) Rietveld plot of the generic G-01, showing Form I of HCTZ and the crystalline excipient lactose monohydrate.

wt $\%$ of active principle ingredient (API) and 85.6(1) wt $\%$ of lactose monohydrate.

\section{Sample G-01}

The Rietveld plot of the G-01 sample is shown in Figure 3, where the peaks of Form I of HCTZ, the crystalline excipient lactose monohydrate and the magnesium stearate can all be observed. The quantitative phase analyses for the sample exhibited 29.2(2) wt $\%$ of API and 70.8(2) wt $\%$ of lactose monohydrate. As the magnesium stearate do not have the crystal structure, it was possible to identify but not quantify.

\section{Sample G-02}

The other generic medicament - sample G-02, has its Rietveld plot shown in Figure 4. The peaks of Form I of HCTZ, the crystalline excipient lactose monohydrate, magnesium stearate, and SLS have all been identified though the latter was not mentioned in the package insert of the medicament. Owing to the fact that the characteristic peaks of SLS $\left(2.68^{\circ}\right.$ and $\left.4.49^{\circ}\right)$ do not overlap with the peaks of any other excipients, it was considered present in the tablet, and hence included in the Rietveld refinement. The quantitative phase analyses for the sample exhibited 23.1 (2) wt\% of API, 76.6 (2) wt\% of lactose monohydrate, and 0.38 (2) wt\% of SLS.
The quantification of SLS was possible because its main peak $\left[2.2^{\circ}\right.$, which corresponds to (100)] appeared in a diffraction region without overlapping with other crystalline phases.

The refinements agreements factor of the Rietveld refinements are given in Table III. The cell parameters were refined to adjust the peak position and the values obtained after the adjustment can also be found in Table III. The cell parameter values, following refinements, have remained close to the values of the crystallographic information framework (CIF) that was used.

The quantitative phase analysis of API of the three samples show significant differences (Sample R 14.4; Sample G-01 29.2; Sample G-02 23.1), indicating that among these formulations differences can be found in the quantity of amorphous excipients.

\section{CONCLUSIONS}

All the tablets (the reference one and the two generic formulations of $25 \mathrm{mg}$ ) exhibited Form I of HCTZ, which is the commercial form of this API.

All samples exhibited the crystal structure of the lactose monohydrate, a crystalline excipient, which peaks have been characterized during the refinements. The generic medicament G-02 exhibited the characteristic peaks of SLS, a crystalline excipient which has not been declared in the package insert of this medicament.

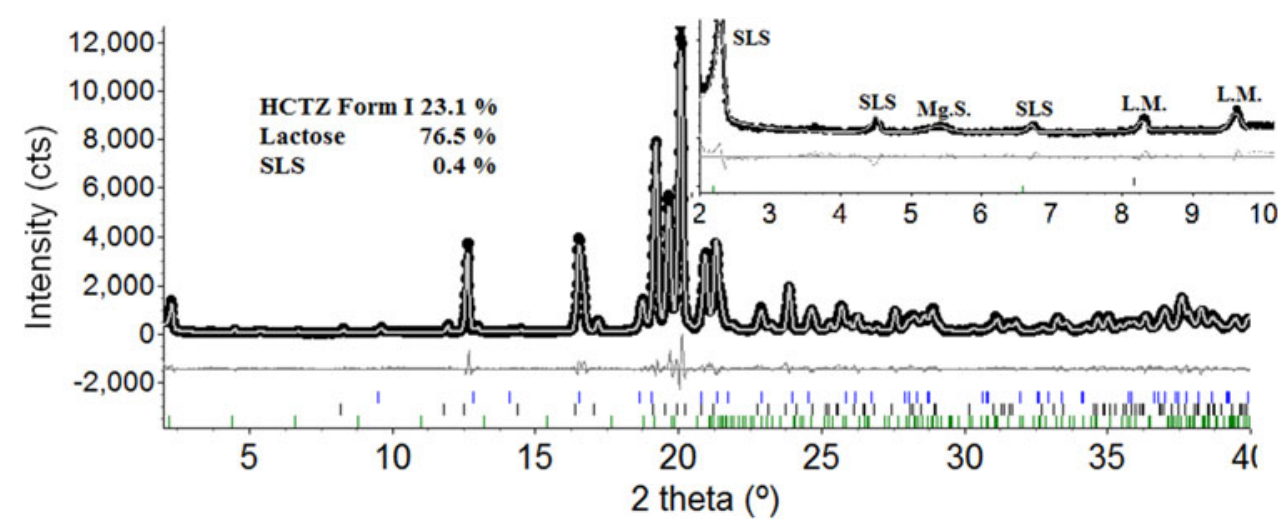

Figure 4. (Color online) Rietveld plot of the sample G-02, showing Form I of HCTZ, the excipient lactose monohydrate (L.M), the magnesium stearate (Mg.S.) and the excipient not mentioned in the package insert: sodium lauryl sulfate (SLS), where the most intense peaks are indicated in the insert. 
TABLE III. Agreement factors and cell parameters obtained from the refinements of the samples $R$, G-01, and G-02.

\begin{tabular}{|c|c|c|c|c|}
\hline & & \multicolumn{3}{|l|}{$\begin{array}{l}\text { Samples } \\
\text { reference }\end{array}$} \\
\hline & & $R$ & G-01 & G-02 \\
\hline \multirow[t]{4}{*}{ Cell parameters (after refinement) } & $a(\AA)$ & $7.430(2)$ & $7.421(1)$ & $7.417(1)$ \\
\hline & $b(\AA)$ & $8.539(1)$ & $8.521(1)$ & $8.530(2)$ \\
\hline & $c(\AA)$ & $10.041(2)$ & $10.034(1)$ & $10.024(2)$ \\
\hline & $\beta\left(^{\circ}\right)$ & $111.82(2)$ & $111.75(2)$ & $111.68(2)$ \\
\hline \multirow[t]{6}{*}{ Agreement factors } & $R_{\mathrm{wp}}(\%)$ & 8.72 & 8.63 & 10.98 \\
\hline & $\chi^{2}$ & 1.90 & 2.93 & 2.46 \\
\hline & $R_{\text {Bragg HCTZ }}^{\mathrm{a}}(\%)$ & 2.31 & 2.95 & 2.54 \\
\hline & $R_{\mathrm{Bragg} \mathrm{LM}}^{\mathrm{b}}(\%)$ & 2.70 & 2.22 & 2.76 \\
\hline & $R_{\mathrm{Bragg} \text { SLS }}^{\mathrm{c}}(\%)$ & - & - & 6.79 \\
\hline & $d$-DW & 0.67 & 0.37 & 0.49 \\
\hline
\end{tabular}

${ }^{\mathrm{a}} \mathrm{HCTZ}$, hydrochlorothiazide.

bLM, lactose monohydrate.

${ }^{\mathrm{c}} \mathrm{SLS}$, sodium lauryl sulfate.

\section{Acknowledgments}

The authors express their gratitude for the work supported by Capes and CNPq, and to FAPESP, a São Paulo State Research Foundation in Brazil.

Balzar, D. (1993). "X-ray diffraction line broadening: modeling and applications to high-Tc superconductors," J. Res. Natl. Inst. Stand. Technol. 98, 321.

Brittain, H. G. (1997). "Spectral methods for the characterization of polymorphs and solvates," J. Pharm. Sci. 86, 405-412.

Cheary, R. W., Coelho, A. A. and Cline, J. P. (2004). "Fundamental parameters line profile fitting in laboratory diffractometers," J. Res. Natl. Inst. Stand. Technol. 109, 1-25.

Chebyshev, P. L. (1854). "Théorie des mécanismes connus sous le nom parallelogrammes," Mémoires des Savants étrangers présentes à l'Academie de Saint-Pétersbourg. 7, 539-586.

Coelho, A. (2007). Topas Academic 44.1 (Coelho Software, Brisbane, Australia) In 4.1 ed., pp. TOPAS ACADEMIC.

Dupont, L. and Dideberg, O. (1972). "Structure cristalline de l'hydrochlorothiazide, C7H8ClN3O4S2," Acta Crystallogr. B 28, 2340-2347.
Florence, A., Johnston, A., Fernandes, P., Shankland, K., Stevens, H. N. E., Osmundsen, S. and Mullen, A. B. (2005). "Powder study of hydrochlorothiazide form II," Acta Crystallogr. E 61, o2798-02800.

Fries, D. C., Rao, S. T. and Sundaralingam, M. (1971). "Structural chemistry of carbohydrates. III. Crystal and molecular structure of 4-O$\beta$-d-galactopyranosyl- $\alpha$-d-glucopyranose monohydrate ( $\alpha$-lactose monohydrate)," Acta Crystallogr. B, Struct. Crystallogr. Cryst. Chem. 27, 994-1005.

Guo, J. F., Jones, M. J. and Ulrich, J. (2010). "Polymorphism of 3,3'-dihydroxy-beta,beta-carotene-4,4'-dione (Astaxanthin)," Chem. Eng. Res. Des. 88, 1648-1652.

Järvinen, M. (1993). "Application of symmetrized harmonics expansion to correction of the preferred orientation effect," J. Appl. Crystallogr. 26, 525-531.

Johnston, A., Florence, A. J., Shankland, N., Kennedy, A. R., Shankland, K. and Price, S. L. (2007). "Crystallization and crystal energy landscape of hydrochlorothiazide," Cryst. Growth Des. 7, 705-712.

Linck, Y. G., Chattah, A. K., Graf, R., Romanuk, C. B., Olivera, M. E., Manzo, R. H., Monti, G. A. and Spiess, H. W. (2011). "Multinuclear solid state NMR investigation of two polymorphic forms of Ciprofloxacin-saccharinate,” Phys. Chem. Chem. Phys. 13, 6590-6596.

Rietveld, H. M. (1969). "A profile refinement method for nuclear and magnetic structures,” J. Appl. Crystallogr. 2, 65-71. 